\title{
CUIDADO DE ENFERMAGEM EM SAÚDE MENTALAO PACIENTE INTERNADO EM HOSPITAL PSIQUIÁTRICO
}

Tatiana Brusamarello ${ }^{1}$, Andréa Noeremberg Guimarães², Márcio Roberto Paes³ ${ }^{3}$ Letícia de Oliveira Borba ${ }^{4}$, Dayane Carla Borille $^{5}$, Mariluci Alves Maftum ${ }^{6}$

RESUMO: Trata-se de uma pesquisa qualitativa descritiva, realizada de fevereiro a maio de $2007 \mathrm{em}$ um hospital especializado em psiquiatria do Paraná. O objetivo foi conhecer como o enfermeiro desenvolve o cuidado de saúde mental ao paciente internado em hospital psiquiátrico. Participaram da pesquisa 7 enfermeiros. Os dados foram obtidos mediante entrevista semi-estruturada e os resultados organizados nas seguintes categorias: o cotidiano da prática do enfermeiro; o cuidado de enfermagem ao paciente e à sua família; cuidado de enfermagem com vistas à autonomia do paciente; despreparo do enfermeiro para cuidar em saúde mental. Os dados demonstraram diversificadas atividades desenvolvidas, entretanto, existe a predominância nas de cunho administrativo. O cuidado direto ao paciente e à sua família é contemplado com menos ênfase. Conclui-se que há necessidade de sistematização do cuidado e realização de educação permanente com foco nos conhecimentos em especial, da relação interpessoal visando uma prática de enfermagem efetiva.

PALAVRAS-CHAVE: Enfermagem; Saúde mental; Assistência de enfermagem.

\section{MENTAL HEALTH NURSING CARE TO PATIENTS HOSPITALIZED IN A PSYCHIATRIC HOSPITAL}

ABSTRACT: It's a descriptive-qualitative research study carried out at a psychiatric hospital in Paraná State/ Brazil from February to May/2007. It aimed: to apprehend how nurses deliver mental health nursing care to patients admitted in a psychiatric hospital. Seven nurses participated in the research study; data were collected by means of a semi-structured interview and categorized as follows: nurses' daily practice; nursing care delivered to patients and family members; nursing care related to patients' autonomy; nurses' disqualification for mental health care. Data disclosed diversified activities performed by nurses, however, administrative ones prevail. Patients' direct care or their families' is less emphasized. It is concluded that care systematization is deemed necessary for a more effective practice as well as ongoing education focusing on knowledge, ultimately interpersonal relationship.

KEYWORDS: Nursing; Mental health; Nursing assistance.

\section{CUIDADO DE LA ENFERMERÍA EN SALUD MENTALAL PACIENTE INTERNADO EN HOSPITAL PSIQUIÁTRICO}

RESUMEN: Se trata de una investigación cualitativa descriptiva, realizada de febrero a mayo de 2007 en un hospital especializado en psiquiatría en el estado de Paraná/Brasil. El objetivo fue conocer cómo el enfermero desarrolla el cuidado de la salud mental con el paciente internado en hospital psiquiátrico. Participaron de la investigación 7 enfermeros. Los datos fueron obtenidos mediante entrevista semiestructurada y los resultados organizados en las siguientes categorías: El cotidiano de la práctica del enfermero; el cuidado de enfermería al paciente y a su familia; cuidado de enfermería con visando la autonomía del paciente; la falta de preparación del enfermero para cuidar en salud mental. Los datos demostraron diversas actividades desarrolladas por el enfermero, sin embargo, existe la predominancia en las de cuño administrativo. El cuidado directo al paciente y a su familia es contemplado con menos énfasis. Conclúyese que existe la necesidad de una sistematización del cuidado y realización de educación permanente con foco en los conocimientos en especial, de la relación interpersonal visando una práctica de enfermería efectiva.

PALABRAS CLAVE: Enfermería; Salud mental; Asistencia de enfermería.

\footnotetext{
${ }^{1}$ Enfermeira. Mestranda do Programa de Pós-Graduação em Enfermagem da Universidade Federal do Paraná-UFPR. Membro do Núcleo de Estudos, Pesquisa e Extensão de Cuidado Humano em Enfermagem-NEPECHE.

${ }^{2}$ Enfermeira. Mestranda do Programa de Pós-Graduação em Enfermagem da UFPR. Membro do NEPECHE.

${ }^{3}$ Enfermeiro. Mestrando do Programa de Pós-Graduação em Enfermagem da UFPR. Membro do NEPECHE.

${ }^{4}$ Enfermeira. Mestranda do Programa de Pós-Graduação em Enfermagem da UFPR. Membro do NEPECHE.

${ }^{5}$ Enfermeira. Mestre em Enfermagem. Membro do NEPECHE.

${ }^{6}$ Enfermeira. Doutora em Enfermagem. Professor Adjunto do Departamento de Enfermagem da UFPR. Vice-coordenadora do NEPECHE.
}

Autor correspondente:

Tatiana Brusamarello

Rua Café Filho, 393 - 83330-030 - Pinhais-PR

Recebido: 01/12/08

E-mail: tatiana_brusamarello@yahoo.com.br

Aprovado: 10/03/09 


\section{INTRODUÇÃO}

A enfermagem lidou, em sua trajetória, com intensa dificuldade com um tema pouco concreto das práticas assistenciais: o sofrimento mental das pessoas. A assistência à saúde à pessoa com transtorno mental variou no decorrer dos tempos devido ao avanço do conhecimento sobre o comportamento humano. No Brasil, essa assistência tem como marco inicial o Hospício D. Pedro II, inaugurado em 1852, no Rio de Janeiro ${ }^{(1)}$.

Naquela época, as religiosas eram responsáveis pelo atendimento às pessoas enfermas, pela administração dos hospícios e santas casas. Naquele contexto, a pessoa com transtorno mental ou vivia nas ruas ou trancafiada nos porões das Santas Casas de Misericórdia, sem tratamento especializado, lhes era fornecido somente o que comer e, às vezes, o que vestir ${ }^{(2)}$.

Com a Proclamação da República, o Estado e o Clero sofreram uma quebra de aliança, resultando na saída das irmãs do hospício, passando a direção deste para os médicos e a assistência para o Estado. Este movimento gerou crise de falta de mão de obra o que levou o Governo da Primeira República, por meio do Decreto $n^{0} 791 / 1890$, criar a primeira escola de enfermagem brasileira ${ }^{(1,3)}$. Com a finalidade de preparar pessoal para trabalhar em hospital psiquiátrico, surgiu a Escola Profissional de Enfermeiros e Enfermeiras, inspirada no modelo francês e ligada ao Hospital Nacional de Alienados. Os cuidados prestados eram basicamente de higiene, alimentação e administração de medicamentos ${ }^{(1,4)}$.

O enfermeiro atuante em Hospício do século XIX era caracterizado como um agente intermediário entre o guarda e o médico, visto que o título prático em enfermagem era conferido a qualquer pessoa com pequena experiência no tratamento dos enfermos. A agressividade e a violência eram características gerais na prática da enfermagem nos hospícios, pois a falta de preparo e ausência de estímulo no trabalho geravam, em suas relações com os alienados, atos violentos, luta e morte ${ }^{(1,3)}$. Neste sentido, a enfermagem que paradoxalmente nasceu no hospício também foi esquecida ou pouco lembrada pela academia e enfermeiros quanto à necessidade de qualificação na área da psiquiatria ${ }^{(1)}$.

Recentes mudanças nos modos de conceber a doença mental e o tratamento dispensado às pessoas com transtornos mentais e suas famílias, impulsionadas pelo movimento da reforma psiquiátrica, vêm requerendo dos profissionais de enfermagem uma prática fundamentada na ética, na cidadania e na humanização. Nas últimas décadas, o campo da saúde mental tem sido fortemente marcado pelo debate decorrente do movimento de Reforma Psiquiátrica que luta pela reorganização e redefinição da atenção à saúde mental no Brasil. Este movimento enfoca a desospitalização e a reinserção social, a implantação de rede de serviços e ações de cunho sanitário, promocional, preventivo e comunitário ${ }^{(5)}$.

As transformações na prática da enfermagem psiquiátrica ocorreram concomitantemente à evolução da assistência nos manicômios e asilos. Entretanto, com a Reforma Psiquiátrica, o cuidado torna-se mais complexo e desenvolvido por uma equipe multidisciplinar, da qual o enfermeiro faz parte. As mudanças na área da saúde mental têm repercussão no papel do enfermeiro; este profissional passa a desempenhar atividades com finalidades terapêuticas por intermédio do relacionamento terapêutico e programas de educação permanente a equipes, pacientes e familiares $^{(6)}$.

O enfermeiro deve ser capaz de compreender o problema da pessoa que sofre mentalmente, entender os efeitos de suas atitudes e habilidade para intervir neste contexto assistencial. Ressalta-se que a relação interpessoal constitui ferramenta importante para o enfermeiro e mediante a qual ser capaz de identificar, descrever e avaliar o efeito dos cuidados que dispensa ao paciente, à família e à comunidade. Este cuidado tem a finalidade de promover a saúde mental, prevenir ou enfrentar a experiência da enfermidade ${ }^{(7)}$.

Diante do exposto, nesta pesquisa tem-se como objetivo conhecer como o enfermeiro desenvolve o cuidado de saúde mental ao paciente internado em hospital psiquiátrico.

\section{METODOLOGIA}

A pesquisa é qualitativa descritiva, desenvolvida de abril a junho de 2007, com 7 enfermeiros que atuam em um hospital colônia público e especializado em psiquiatria no Paraná.

Os dados foram obtidos mediante entrevista semi-estruturada cujo roteiro na primeira parte compreendeu dados de identificação e qualificação profissional e na segunda as seguintes questões abertas: Relate as atividades/ações que você desenvolve no seu dia-a-dia; Como você percebe o papel do enfermeiro no cuidado ao paciente com transtorno mental? Quais sugestões você teria para 
implementar/melhorar as atividades de enfermagem em saúde mental?

O projeto de pesquisa foi aprovado pelo Comitê de Ética e Pesquisa do Setor de Ciências da Saúde da Universidade Federal do Paraná, sob registro CEP/ SD 341.021.07.04. Os enfermeiros participantes receberam informações a respeito da metodologia e objetivos da pesquisa e assinaram o Termo de Consentimento Livre e Esclarecido de acordo com a Resolução 196/96 do Conselho Nacional de Saúde ${ }^{(8)}$.

A análise dos dados foi realizada de acordo com o proposto por Minayo ${ }^{(9: 234-8)}$ que inclui as fases de: ordenação dos dados, classificação e análise final dos temas que emergirem do material coletado. A fase de Ordenação dos dados inclui a transcrição de fitas cassete; releitura do material; organização dos relatos em determinada ordem e organização dos dados de observação. A fase de Classificação dos dados foi dividida em leitura exaustiva e repetida dos textos, também denominada de leitura flutuante; constituição de um "Corpus" ou de vários "Corpos" de comunicações. Na Análise Final ocorreu o movimento entre o empírico e o teórico, o concreto e abstrato, o particular e o geral. A totalização final consistiu no encontro das especificidades do objeto pela prova do vivido. A análise temática comporta um feixe de relações e pode ser graficamente apresentada através de uma palavra, uma frase, um resumo.

\section{APRESENTAÇÃO E DISCUSSÃO DOS DADOS}

Quanto ao gênero, quatro enfermeiros são do sexo masculino e três do feminino. Essa predominância relaciona-se com a história da enfermagem nos hospícios brasileiros do século passado, visto que houve a inversão da ordem da feminização da profissão devido à necessidade de força física para o controle dos pacientes. Isso ocorria porque medidas terapêuticas como vigilância e punição eram tarefas fundamentais da enfermagem ${ }^{(1)}$.

Seis sujeitos possuem especialização em áreas não relacionadas à saúde mental, o que reflete a escassez de oferta de cursos específicos na referida área. Isso é confirmado na pesquisa ${ }^{(10)}$ em que nas entrevistas realizadas a 19 docentes dos cursos de enfermagem do Paraná, encontrou-se que a maioria fez mais de uma especialização em áreas que não da especialidade de atuação da saúde mental.

A vinculação profissional na rede pública estadual contempla jornada de trabalho de oito horas diárias, entretanto houve predominância (cinco) de dupla jornada. Isto é corroborado por Pitta ${ }^{(11)}$ ao discorrer que o regime de turnos e plantões abre a perspectiva de dupla jornada de trabalho, comum entre os trabalhadores da saúde, principalmente em um país em que os baixos salários pressionam para tal.

\section{AS CATEGORIAS TEMÁTICAS}

Ao proceder a análise dos dados emergiram as seguintes categorias: o cotidiano da prática do enfermeiro; o cuidado de enfermagem ao paciente e à sua família; cuidado de enfermagem com vistas à autonomia do paciente; despreparo do enfermeiro para cuidar em saúde mental.

\section{O cotidiano da prática do enfermeiro}

Os enfermeiros externaram predominância no uso do maior tempo de trabalho na realização de atividades administrativas e burocráticas tais como: supervisão, remanejamento de pessoal, orientação para equipe de enfermagem, participação em reuniões com a equipe multiprofissional e manutenção do ambiente relativo ao mobiliário, instrumental e estrutura física, como relatos abaixo:

Minha atividade é supervisão. Converso com os funcionários do plantão. Passo nas unidades, vejo se estão todos da escala, se falta alguém, se precisa remanejar (E.3).

Conversar com a enfermagem e ver se os que estão nos setores estão bem. Às vezes falta um funcionário, então você não pode deixar o funcionário sozinho. Fazer um apanhado geral de como está o hospital naquele momento (E.6).

A gente desenvolve atividades com a equipe, nas reuniões, acompanha os funcionários [...] vê as coisas que precisam de conserto (E.4).

Os relatos corroboram a um estudo bibliográfico de publicações de enfermagem sobre a atividade que o enfermeiro em saúde mental na qual a análise dos textos explicitou que o enfermeiro é o profissional da equipe de saúde mental que menos realiza cuidados diretos à clientela e ocupa a maior parte de seu tempo com atividades de organização do trabalho. Também, que os enfermeiros se ocupam, muitas vezes de forma 
prioritária, com atividades que têm por finalidade a organização do trabalho dos demais profissionais ${ }^{(6)}$.

Embora o papel do enfermeiro em saúde mental seja o de agente terapêutico, cujo objetivo fundamental é auxiliar o paciente a aceitar a si próprio e a melhorar as suas relações pessoais( ${ }^{(6)}$, na prática centra-se, principalmente, no desenvolvimento de atividades burocrático-administrativas, com escassa ou nenhuma atuação técnico-assistencial específica ${ }^{(3)}$.

\section{O cuidado de enfermagem ao paciente e sua família}

O enfermeiro desenvolve cuidado ao paciente e familiares em proporções menores quando comparadas às administrativas. A interação acontece quando há um momento ou uma oportunidade, não faz parte do planejamento do cuidado. Um dos enfermeiros relatou que acompanha o paciente desde a admissão, acolhe o familiar e realiza a consulta de enfermagem. Em uma das falas é explicitado o relacionamento interpessoal, no qual o enfermeiro utiliza ferramentas da comunicação para a realização do cuidado.

Quando é possível, fico na unidade, faço a evolução dos pacientes, chamo um por um, faço a consulta de enfermagem. Às vezes faço assembléia, reúno o grupo e discutimos sobre o tratamento, como estão, quando pensam em sair de alta, oriento a continuidade do tratamento em CAPS. Acompanho os internamentos com o paciente e o familiar, faço acolhimento, faço uma pré-consulta de enfermagem (E.6).

Procuro primeiro escutá-los, acolhê-los e orientálos, ver de que forma posso ajudá-los, esclarecer as dúvidas, como posso integrá-los na unidade. Faço seminários, dinâmicas de grupo, procuro trabalhar [...] resgatá-los como cidadãos, esclarecer sobre seus direitos, lembrá-los que também tem deveres. Procuro trabalhar a percepção deles sobre a doença (E.7).

Na prática, o enfermeiro precisa assumir funções de planejamento, organização, coordenação, execução e avaliação dos serviços de enfermagem ${ }^{(12)}$, porém, em sua maioria, o cuidado direto ao paciente é realizado pelo pessoal técnico e auxiliar. O exercício da consulta de enfermagem é garantido ao enfermeiro pela Lei do Exercício Profissional ${ }^{(12)}$ mas a sua efetivação nos serviços de saúde consiste em um desafio, pela escassez de profissionais, ausência de espaço físico, carência de aperfeiçoamento e outros obstáculos para sua realização e, quando se trata da área da saúde mental, esta situação torna-se mais acentuada.

Somente dois enfermeiros mencionaram o cuidado à família como essencial e que o contato com o familiar acontece nos momentos de alta e de internação. Sendo assim, são realizadas reuniões em grupo para esclarecer as formas de continuidade do tratamento e a importância da qualidade de vida tanto do paciente como do familiar, conforme se observa no relato a seguir:

Trabalho muito a família, é essencial. Tenho contato com a família no individual, em dois momentos: quando coincide no internamento $e$ quando coincide na alta. Faço reuniões em grupos de familiares, e trabalho a continuidade do tratamento, reforço a importância dos grupos de apoio, a qualidade de vida deles (E.7).

O relacionamento terapêutico torna-se efetivo quando o paciente e a família passam a ser o foco na prática profissional do enfermeiro. É necessário estabelecer uma relação positiva com a família e incentivar sua participação nos cuidados permitidos pelo estabelecimento, a manutenção dos laços afetivos e encorajando a comunicação ${ }^{(13)}$. O uso da comunicação para a realização do cuidado é imprescindível e cabe ao enfermeiro atender o paciente e seu familiar de forma integral levando em consideração o uso deste instrumento ao planejar e desenvolver o cuidado ${ }^{(14)}$.

Assim como a loucura, a família também passou por mudanças conceituais e estruturais ao longo dos anos, porém até hoje a convivência com uma pessoa com transtorno mental gera conflitos no ambiente familiar. Sentimentos como medo, culpa, impotência, raiva e vergonha estão presentes no cotidiano daqueles que convivem com o sofrimento psíquico, o que pode dificultar as relações e, conseqüentemente, o processo de tratamento e reabilitação. A família precisa ser preparada para participar, opinar, decidir e se coresponsabilizar pelo cuidado ${ }^{(15)}$.

O trabalho com os familiares é mais uma área em que os profissionais de enfermagem precisam desenvolver habilidades, pois a família é fundamental na manutenção da pessoa com transtorno mental fora da instituição psiquiátrica, considerada um dos pilares fundamentais para o sucesso da reforma psiquiátrica, 
o que reforça a necessidade dela ser preparada e apoiada pelos profissionais ${ }^{(16)}$.

\section{Cuidado de enfermagem com vistas à autonomia do paciente}

Os sujeitos relataram a importância que atribuem ao cuidado, referiram trabalhar o resgate da autonomia dos pacientes, o cuidado de si, higiene, alimentação, medicação, o saber se conhecer e perceber quando ele necessita ajuda.

Trabalho o autocuidado, que não inclui só banho, escovar dente e comer, inclui saber qual o remédio que tem de tomar e que horas, saber se perceber quando está com problema ou não, quando dá prá fazer sozinho ou precisa ajuda, se conhecer, saber cuidar de si (E.2).

Uma coisa que percebo é a falta do autocuidado, eu vejo nas piores situações que tem é dele não conseguir se olhar no espelho, não conseguir se tocar, a percepção de limites que ele perde. Isso a enfermagem pode no dia a dia ir resgatando (E.1).

A maior parte das ações que o enfermeiro realiza, deve buscar estimular o paciente ao autocuidado, visando desenvolver suas capacidades e habilidades para lidar da melhor forma possível com as dificuldades que possui. Portanto, as ações de cuidado devem ser organizadas objetivando valorizar o potencial sadio que cada pessoa possui e capacitá-lo a conviver com os outros, a reconhecer suas potencialidades e limites de forma a procurar por tratamento, prevenção e promoção da sua saúde mental ${ }^{(10)}$.

O profissional que atua na área de saúde mental deve ser capaz de estabelecer relacionamentos terapêuticos saudáveis, produzindo novas possibilidades de reabilitação psicossocial. Isso inclui educar os pacientes para o autocuidado, possibilitar a melhora de sua auto imagem e atentar para suas necessidades básicas ${ }^{(3)}$.

\section{Despreparo do enfermeiro para cuidar em saúde mental}

Os enfermeiros relataram que sentem dificuldade para realizar cuidado à pessoa em sofrimento mental e que isso decorre da falta de preparo que os acompanha desde a formação profissional. Os relatos evidenciam a falta de preparo e a insegurança gerada por esta condição. Alegam que não tiveram conteúdo suficiente na graduação e que a carga horária reduzida não ensejou oportunidade de um contato maior com pessoas com transtorno mental durante a prática acadêmica.

Acho que é preciso um preparo melhor para cuidar do paciente psiquiátrico, com mais paciência, mais centrado, mais equilibrado [...] eu vejo que falta para nós enfermeiros, um pouco mais de preparo (E.5).

É muito difícil a abordagem ao doente mental, pois durante a formação a gente não tem esta experiência a carga horária é muito reduzida [...] é muito difícil fazer um contato, estabelecer um relacionamento, porque a gente não tem isso claro (E.1).

A realidade mencionada pelos sujeitos está se transformando. Hoje a disciplina de saúde mental começa a ser reconhecida como essencial na formação dos profissionais da enfermagem, que necessitam aprender a usar os conhecimentos que embasam a compreensão do ser humano, das motivações e comportamentos, bem como interagir com o paciente no momento crítico de sofrimento mental ${ }^{(10)}$. Porquanto, uma capacitação deve incluir a ênfase em conteúdos que ajudem a compreender e desenvolver o processo de relação interpessoal entre profissional e paciente.

Trabalhar com as pessoas em sofrimento mental exige do enfermeiro, cuidar respeitando os princípios da cidadania e dos direitos humanos, participar na construção de planos terapêuticos individuais e enfatizar em suas ações o sujeito e as suas potencialidades ${ }^{(17)}$. Além disso, necessita estar atualizado para acompanhar as mudanças advindas do desenvolvimento técnico-científico e das políticas de saúde mental ${ }^{(18)}$.

\section{CONSIDERAÇÕES FINAIS}

As constantes transformações na profissão de enfermagem, decorrentes dos avanços nos processos do cuidar em saúde mental, estão incitando o enfermeiro a rever suas atribuições como profissional, transformar seu processo de trabalho, adaptar-se ao cuidar terapêutico, usando a comunicação e o relacionamento interpessoal para evoluir em suas produções e ações científicas. 
Na realização deste estudo, observou-se a necessidade de investimento na melhoria do cuidado de enfermagem à pessoa com transtorno mental e sua família, de modo a lhes assegurar melhor qualidade de vida. Dentre estes, ressalta-se a necessidade de os enfermeiros se atualizarem a fim de ampliar suas competências, adaptando-se às novas modalidades de tratamento. É imprescindível que este profissional desenvolva o olhar crítico junto da equipe de enfermagem para apreender as necessidades de educação permanente.

Espera-se que este estudo colabore para instigar o enfermeiro à compreensão da importância de que representa no cuidado ao portador de transtorno mental e à sua família e que avance em uma prática de cuidado; que extrapole a repetição de ações e cuidados, sem questioná-los e avaliá-los. O diferencial do profissional está nas mudanças que pode realizar por meio do saber e do fazer, tornando-se assim um líder dentro dos novos arranjos estruturais decorrentes da implantação das novas políticas de saúde mental. Também, espera-se que estudo auxilie no despertar de novas investigações a respeito de um tema complexo, como é o trabalho do enfermeiro em saúde mental.

\section{REFERÊNCIAS}

1. Miranda CL. O parentesco imaginário: história e representação social da loucura nas relações do espaço asilar. São Paulo: Cortez; 1994.

2. Ogata MN. Contribuição à história da enfermagem psiquiátrica brasileira [dissertação]. Ribeirão Preto (SP): Escola de enfermagem de Ribeirão Preto. Universidade de São Paulo; 1992.

3. Oliveira AGB, Alessi NP. O trabalho de enfermagem em saúde mental: contradições e potencialidades atuais. Rev Latino-Am Enferm. 2003; 3(11):333-40.

4. Taylor CM. Fundamentos de enfermagem psiquiátrica de Mereness. 13ª ed. Porto Alegre: Artes Médicas; 1992.

5. Amarante P. O homem e a serpente: outras histórias para a loucura e a psiquiatria. Rio de Janeiro: FIOCRUZ; 1996.

6. Bertoncello NM, Franco FCP. Estudo bibliográfico de publicações sobre a atividade administrativa da enfermagem em saúde mental [periódico na Internet]. Rev Latino-Am Enferm. 2001 [acesso em 2007 Out 02] 9(5):83-90. Disponível: www.scielo.br/pdf/rlae/v9n5/ 7803.pdf.
7. Travelbee J. Intervencion en enfermería psiquiatrica: el processo de la relacion de persona a persona. $2^{\mathrm{a}}$ ed. Colômbia: OPAS/OMS; 1982.

8. Ministério da Saúde (BR). Conselho Nacional de Saúde. Diretrizes e normas regulamentadoras de pesquisas envolvendo seres humanos. Resolução $n^{\circ}$. 196, de 10 de outubro de 1996. Brasília; 1996.

9. Minayo MCS. O desafio do conhecimento: pesquisa qualitativa em saúde. $3^{\text {a }}$ ed. São Paulo: Hucitec; 2004.

10. Maftum MA, Alencastre MB. O cenário da qualificação docente de enfermagem em saúde mental no Paraná. Rev Nursing. 2008; 11(124):404-10.

11. Pitta A, organizadora. Reabilitação psicossocial no Brasil. São Paulo: Hucitec; 1996.

12. Brasil. Lei n. 7.498, de 25 de junho de 1986. Dispõe sobre a regulamentação do exercício da enfermagem e dá outras providências. Conselho Federal de Enfermagem [acesso em 2008, mai 22]. Disponível: www.portalcofen.gov.br

13. Hanus M, Marchal V. Psiquiatria e cuidados de enfermagem. São Paulo: Andrei; 2003.

14. Roehrs H, Maftum MA, Stefanelli MC. A comunicação terapêutica sustentando a relação interpessoal entre adolescente e professor do ensino fundamental[periódico na Internet]. Online Braz J Nurs [acesso 2008 Set 16] 6(2). Disponível: www.uff.br/ objnursing/.php/nursing/article/view/j.16764285.2007.1053/230.

15. Oliveira AGB, Marcon SR. Família e transtorno mental: reflexões teórico-práticas. In: Oliveira AGB, organizadora. Ensino de enfermagem: temas e estratégias interdisciplinares. Cuiabá: UFMT; 2006.

16. Waidman MAP, Elsen I, Marcon SS. Possibilidades e limites da teoria de Joyce Travelbee para a construção de uma metodologia de cuidado à família. [periódico da Internet]. Rev Eletrôn Enferm, 2006 [acesso em 2008, Ago 21] 8(2): 282-291 Disponível: www.portalbvsenf.eerp.usp.br

17. Girade MG, Cruz EMNT, Stefanelli MC. Educação continuada em enfermagem psiquiátrica: reflexão sobre conceitos. Rev Esc Enferm USP. 2006; 2(40):105-10.

18. Barreto MS, Büchele F, Coelho EBS. O cuidado com o sofredor psíquico institucionalizado. Cogitare Enferm. 2008; 13(4):607-11. 